J. AmEr. Soc. Hort. ScI. 127(6):944-946. 2002.

\title{
Linkage Equilibrium among Tightly Linked RFLPs and the Ms Locus in Open-pollinated Onion Populations
}

\author{
Ali Fuat Gökçe \\ Horticulture Department, Uludag University, Gorukle, Bursa 16059, Turkey \\ Michael J. Havey ${ }^{1}$ \\ Agricultural Research Service, USDA, Department of Horticulture, 1575 Linden Drive, University of \\ Wisconsin, Madison, WI 53706
}

\begin{abstract}
AdDitional INDEX WORDs. Allium cepa, cytoplasmic-genic male sterility, male-fertility restoration, restriction fragment length polymorphisms

Abstract. Cytoplasmic male sterility (CMS) in onion (Allium cepa L.) is conditioned by the interaction of the male-sterile (S) cytoplasm with recessive alleles at a single nuclear male-fertility restoration locus $(M s)$. In order to seed propagate male-sterile plants (S msms), onion breeders must identify maintainer lines possessing normal (N) male-fertile cytoplasm and homozygous recessive at the $M s$ locus $(\mathrm{N}$ msms). Molecular markers have been identified distinguishing $\mathbf{N}$ and $\mathrm{S}$ cytoplasms and closely linked to the nuclear $M s$ locus. In this study, we evaluated testcross progenies from randomly selected N-cytoplasmic plants from three open-pollinated populations for nuclear restoration of male fertility over at least three environments. The $M s$ locus and linked restriction fragment length polymorphisms $(0.9$ and $1.7 \mathrm{cM})$ were at linkage equilibrium in all three open-pollinated onion populations, indicating that these linked markers cannot be used to identify maintaining genotypes in open-pollinated onion populations. However, cytoplasmic evaluations were effective in reducing the number of testcrosses required to identify CMS-maintaining genotypes.
\end{abstract}

Hybrid-onion (Allium cepa L.) seed is produced using cytoplasmic-genic male sterility (CMS). Jones and Clarke (1943) were the first to describe the genetic basis of the nuclear-cytoplasmic interaction conditioning CMS. In onion, male sterility is conditioned by the male-sterile (S) cytoplasm and the homozygous recessive genotype at one nuclear male-fertility restoration locus $(M s)$. Malesterile lines $(S \mathrm{msms})$ are seed propagated by crossing with a maintainer line possessing normal $(\mathrm{N})$ male-fertile cytoplasm and the homozygous recessive genotype at the restorer locus ( $\mathrm{N} \mathrm{msms)}$ (Jones and Davis, 1944). Because onion is biennial, it takes four to eight years to determine if maintainer lines ( $N$ msms) can be extracted from a population or segregating family (Havey, 1995).

Open-pollinated (OP) onion populations can possess both $\mathrm{N}$ and S cytoplasms and the dominant and recessive alleles at the $M s$ locus. Havey (1993) used organellar DNA polymorphisms to demonstrate that the OP populations 'Brigham Yellow Globe' (BYG), 'Mountain Danvers' (MD), and 'Sapporo-ki' (SKI) possess between 20\% and $40 \%$ of S cytoplasm. Male fertility restoration in testcrosses revealed that all three populations possess the dominant allele at $M s$ at allelic frequencies of $\approx 0.60,0.73$, and 0.62 , respectively (Havey and Randle, 1996). The long-day storage onion populations BYG, $\mathrm{MD}$, and SKI were historically grown in Michigan and Colorado in the United States and on the island of Hokkaido in Japan, respectively. The likely progenitor populations of BYG, MD, and SKI are 'Yellow Globe Danvers' (YGD) and 'Southport Yellow Globe' (SYG), grownhistorically in the northeastern United States (Goldman et al., 2000). However both YGD and SYG possess trace to no detectable levels of S cytoplasm (Havey, 1993) and very low frequencies $(\leq 0.01)$ of the dominant $M s$ allele (Havey and Randle, 1996). An explanation for these differences is that unconscious

Received for publication 28 May 2002. Accepted for publication 20 Aug. 2002. Names are necessary to report factually on available data; however, the USDA neither guarantees nor warrants the standard of the product, and the use of the name by USDA implies no approval of the product to the exclusion of others that may also be suitable. The technical help of Mark Petrashek is gratefully acknowledged. A.F. Gökçe was a graduate student in the Department of Horticulture, University of Wisconsin, and received support from the Turkish Ministry of Education.

${ }^{1}$ To whom correspondence should be addressed; e-mail mjhavey@facstaff.wisc.edu. selection or random genetic drift increased the frequencies of $\mathrm{S}$ cytoplasm and the dominant $M s$ allele as the cultivation of storage onion populations spread from the northeastern United States across the northern United States and ultimately to Japan (Goldman et al., 2000). A second explanation is that seed and/or bulb mixtures could have occurred, introducing both $\mathrm{S}$ cytoplasm and the dominant $M s$ allele into BYG, MD, and/or SKI or one of their progenitor populations, as previously reported for United States short-day onion populations (Havey and Bark, 1994). There exist OPlong-day storage populations possessing high frequencies of S cytoplasm and the dominant $M s$ allele, such as 'Pukekohe Longkeeper' (Havey, 1993). If a seed or bulb mixture occurred recently introducing the dominant $M s$ allele into BYG, MD, SKI, or their progenitor population, linkage disequilibrium may still exist between the dominant $M s$ locus and closely linked loci.

Gökçe et al. (2002) identified restriction fragment length polymorphisms (RFLPs) tightly linked to the $M s$ locus, facilitating the identification of plants carrying the recessive $m s$ allele. Although molecular markers can be used in segregating families at maximum linkage disequilibrium, there are no published assessments of linkage equilibrium among linked genetic markers in onion and it is not known if molecular markers tightly linked to $M s$ will be effective in the selection of maintainer lines from OP populations. In this study, we established the cytoplasms and genotypes at $M s$ and tightly linked molecular markers for plants randomly selected from $\mathrm{BYG}, \mathrm{MD}$, and SKI to assess linkage equilibrium and to determine if marker facilitated selection for maintainer lines can be applied to $\mathrm{OP}$ onion populations.

\section{Materials and Methods}

The origins of OP populations BYG, MD, and SKI were previously reported (Havey, 1995). From BYG, MD, and SKI, 35,67 , and 91, respectively, male-fertile bulbs were randomly selected and self-pollinated and testcrossed to male-sterile ( $\mathrm{S}$ msms) plants (MSU611-1A x MSU611B or B3350A x B2352B) as described by Pike (1986). Genomic DNAs of $\mathrm{S}_{1}$ families were 


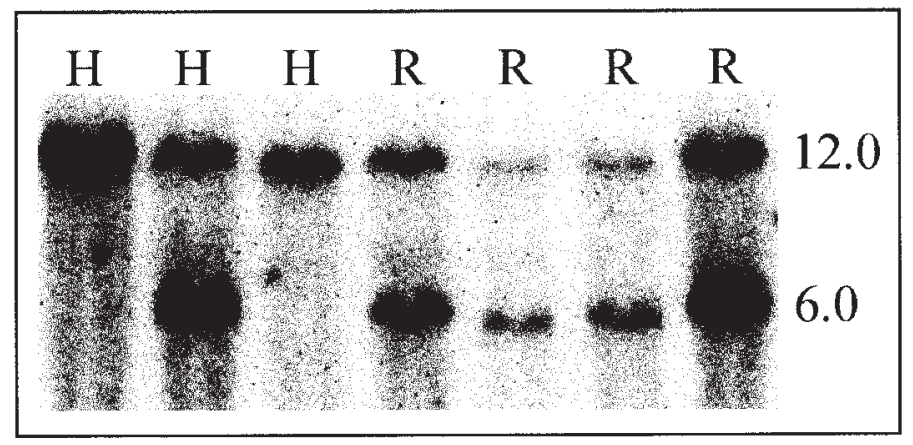

Fig. 1. Autoradiogram showing allelic restriction fragment length polymorphisms revealed by AOB272-EcoRI for $\mathrm{S}_{1}$ families from randomly selected plants from the open-pollinated population 'Brigham Yellow Globe'. Fragment sizes in kilobases are shown on right. Genotypes $(\mathrm{H}=$ heterozygous and $\mathrm{R}=$ homozygous recessive) at $M s$ for these $\mathrm{S}_{1}$ families are shown across the top and were based on segregation of male fertility among progenies from testcrosses to male-sterile plants.

extracted from leaf tissue bulked from at least 50 seedlings and purified through $\mathrm{CsCl}$ gradients (Havey, 1991b). N and S cytoplasms were identified using chloroplast characters 2, 4, and 41 (Havey, 1993); B3350B (N) and Spartan Banner 80 (S) were used as cytoplasmic controls (origins described by Havey, 1991a). Seed from testcrosses with N-cytoplasmic (male-fertile) plants was planted and bulbs were harvested, vernalized, randomly assigned to field plots, and allowed to flower. The frequencies of male-fertile and male-sterile testcross progenies were determined by visual inspection of umbels over at least 3 years in Madison, Wisc. The genotypes at the $M s$ locus for $\mathrm{S}_{0}$ plants were assigned based on segregations of male fertility in the testcross families.

Linkages of RFLPs around the $M s$ locus have been previously reported (Gökçe et al., 2002). Genotypes at nuclear RFLPs linked [AOB272-E1 (0.9 cM), API63-E5 (2.6 cM), AOB186-E5 (8.6 $\mathrm{cM})$, and API27-E1 (12.7 cM)] and unlinked [AOB41-H3 (72.3 $\mathrm{cM})$ ] to $M s$ were established for each $\mathrm{N}$-cytoplasmic $\mathrm{S}_{1}$ family from BYG, MD, and SKI as previously described (Gökçe et al., 2002; King et al., 1998). We also scored genotypes for each $S_{1}$ family from BYG, MD, and SKI for cosegregating (AOB186-E5 and AOB232-E5) or tightly linked (AOB272-EI and API63-E5 at 1.7 cM) RFLPs (Gökçe et al., 2002; King et al., 1998). Chi-square analyses were used to assess goodness-of-fit between observed frequencies of genotypes at $M s$ and RFLPs with those expected at linkage equilibrium. Fischer's protected test was also used because it is less sensitive to smaller expected frequencies than chi-square analysis (Wier, 1990). The numbers of testcrosses required to identify maintainer genotypes among N-cytoplasmic plants in BYG, MD, and SKI were calculated using the trait recovery program of Mansur et al. (1990) as described by Havey (1995).

\section{Results and Discussion}

ASSESSMENT OF LINKAGE EQUILIBRIUM IN THREE OP ONION POPULATIONS. We randomly sampled N-cytoplasmic plants from BYG, MD, and SKI and scored the genotypes at the $M s$ locus and linked RFLPs (Fig. 1). The Ms locus and the most tightly linked RFLP (AOB272-E1 at $0.9 \mathrm{cM}$ ) were at linkage equilibrium in all three OP populations (Table 1). RFLPs showing looser (API63E5, AOB186-E5, and API27-E1) or no (AOB41-H3) linkage to $M s$ were also at linkage equilibrium in the three populations (individual probabilities reported in Gökçe, 2001). The cosegregating RFLPs AOB186-E5 and AOB232-E5 (King et al., 1998) were at linkage equilibrium, $P=0.447$ for $\mathrm{BYG}, P=0.921$ for MD, and $P=0.991$ for SKI. AOB272-E1 and API63-E5 showed linkage at $1.7 \mathrm{cM}$ (Gökçe et al., 2002) and were at linkage equilibrium in SKI $(P=0.834)$. Fischer's protected tests gave the same results as the chi-square tests.

These analyses demonstrated that adequate generations of random mating have occurred in all three OP populations to reach linkage equilibrium, even among tightly linked loci. It is unlikely that the presence of $\mathrm{N}$ and $\mathrm{S}$ cytoplasms and the dominant and recessive alleles at the $M s$ locus in BYG, MD, and SKI were due to a recent seed or bulb mixture. The populations BYG, MD, and SKI possessed the same sized RFLPs as YGD and SYG (Bark and Havey, 1995), indicating no evidence of contamination with diverse S-cytoplasmic population(s). The most probable expla-

Table 1. Frequencies of normal (N) male-fertile cytoplasm in the open-pollinated populations 'Brigham Yellow Globe' (BYG), 'Mountain Danvers' (MD), and 'Sapporo-Ki' (SKI) and genotypes at the $M s$ locus and the restriction fragment length polymorphism AOB272-EcoRI for randomly selected N-cytoplasmic onion plants from these three populations. Linkage equilibrium was tested by goodness-of-fit of observed to expected genotypic frequencies at AOB272-EcoRI based on allelic frequencies.

\begin{tabular}{|c|c|c|c|c|c|c|c|}
\hline \multirow[b]{2}{*}{ Population } & \multirow[b]{2}{*}{$\begin{array}{l}\text { Frequency of } \\
\mathrm{N} \text { cytoplasm }\end{array}$} & \multirow[b]{2}{*}{$\begin{array}{c}\text { Genotypes at } \\
M s \text { locus }\end{array}$} & \multirow[b]{2}{*}{$\begin{array}{c}\text { Proportion }^{\mathrm{z}} \text { of } \\
\text { genotypes } \\
\text { at } M s\end{array}$} & \multicolumn{3}{|c|}{ Plants with genotypes at AOB272-EcoRI ${ }^{\mathrm{y}}$} & \multirow[b]{2}{*}{$P^{\mathrm{w}}$} \\
\hline & & & & $\begin{array}{c}\text { Homozygous } \\
\text { for } \\
12.0 \mathrm{~kb}\end{array}$ & Heterozygous & $\begin{array}{c}\text { Homozygous } \\
\text { for } \\
6.0 \mathrm{~kb}^{\mathrm{x}}\end{array}$ & \\
\hline \multirow[t]{3}{*}{$\overline{\mathrm{BYG}}$} & 0.77 & $M s M s$ & 0.08 & 2 & 0 & 0 & 0.373 \\
\hline & & Msms & 0.59 & 7 & 7 & 0 & \\
\hline & & msms & 0.33 & 3 & 4 & 1 & \\
\hline MD & & msms & 0.24 & 7 & 4 & 0 & \\
\hline \multirow[t]{3}{*}{ SKI } & 0.76 & $M s M s$ & 0.46 & 17 & 5 & 0 & $0.209^{c}$ \\
\hline & & Msms & 0.39 & 1 & 21 & 0 & \\
\hline & & msms & 0.15 & 1 & 7 & 0 & \\
\hline
\end{tabular}

${ }^{\mathrm{z}}$ Genotypic frequencies shown only for plants possessing $\mathrm{N}$ cytoplasm.

${ }^{y}$ Alleles at AOB272/EcoRI were established by King et al. (1998) or this research. Only the 12.0 and 6.0 kb fragments were observed among plants from these three open-pollinated populations.

${ }^{x}$ No homozygotes for the $6.0 \mathrm{~kb}$ fragment were observed in SKI and this class was excluded from the test.

wProbabilities are reported for chi-squared tests; Fischer's protected test gave the same results. 
nations for the increased frequencies of $\mathrm{S}$ cytoplasm and the dominant $M s$ allele in BYG, MD, and SKI, as compared to YGD and SYG, are either random drift in the progenitor OP population(s) as cultivation of long-day storage onions spread from the northeastern United States, through the midwestern and western United States, and then to Japan, or contamination of the progenitor OP population with a closely related long-day storage population possessing high frequencies of both $\mathrm{S}$ cytoplasm and the dominant $M s$ allele. However, drift or contamination must have occurred long enough ago to allow any disequilibrium among tightly linked loci to reach linkage equilibrium.

MoleCUlaR-FACILITATED SELECTION OF MAINTAINER LINES IN ONION. Because the linked RFLPs and $M s$ are in linkage equilibrium, these molecular markers cannot be used to identify maintaining genotypes among plants from OP onion populations. However, the nuclear markers will be useful after generating linkage disequilibrium by crossing among CMS-restoring and maintaining genotypes (Gökçe et al., 2002). The predominance of linkage equilibria revealed in this study complicates the application of marker-facilitated selection to OP onion populations. Future efforts will focus on isolation of the onion genomic region carrying the $M s$ locus to clone this specific locus or identify physically linked markers showing linkage disequilibrium useful for the characterization of alleles at $M s$.

Even though these nuclear RFLPs cannot be used to predict genotypes at $M s$ in these open-pollinated populations, the number of testcrosses required to be $99 \%$ confident of identifying a CMSmaintainer genotype can be reduced by $25 \%, 24 \%$, and $24 \%$ for $\mathrm{BYG}, \mathrm{MD}$, and SKI, respectively, by selecting for testcrossing only those plants possessing $\mathrm{N}$ cytoplasm. These results conclusively demonstrate that molecular characterization of the cytoplasm is an effective technology to more efficiently identify CMS-maintaining genotypes from OP onion populations possessing both $\mathrm{N}$ and $\mathrm{S}$ cytoplasms, as previously proposed by Havey (1995).

\section{Literature Cited}

Bark, O.H. and M.J. Havey. 1995. Similarities and relationships among open-pollinated populations of the bulb onion as estimated by nuclear
RFLPs. Theor. Appl. Genet. 90:607-614.

Gökçe, A.F. 2001. Molecular tagging of the male-fertility restoration locus and its selection in onion (Allium cepa $\mathrm{L}$.). $\mathrm{PhD}$ thesis. Univ. Wis.-Madison.

Gökçe, A.F., J. McCallum, Y. Sato, and M.J. Havey. 2002. Molecular tagging of the Ms locus in onion. J. Amer. Soc. Hort. Sci. 127:576-582.

Goldman, I.L., G. Schroeck, and M.J. Havey. 2000. History of public onion breeding programs and pedigree of public onion germplasm releases in the United States. Plant Breeding Rev. 20:67-103.

Havey, M.J. 1991a. History of releases from the onion breeding program of the United States Department of Agriculture. Allium Improv. Nwslt. $1: 50-54$.

Havey, M.J. 1991b. Phylogenetic relationships between cultivated Allium species from restriction enzyme analysis of the chloroplast genome. Theor. Appl. Genet. 81:752-757.

Havey, M.J. 1993. A putative donor of S-cytoplasm and its distribution among open-pollinated populations of onion. Theor. Appl. Genet. 86:128-134

Havey, M.J. 1995. Cytoplasmic determinations using the polymerase chain reaction to aid in the extraction of maintainer lines from openpollinated populations of onion. Theor. Appl. Genet. 90:263-268.

Havey, M.J. and O.H. Bark. 1994. Molecular confirmation that sterile cytoplasm has been introduced into open-pollinated populations of Grano-type onion. J. Amer. Soc. Hort. Sci. 119:90-93.

Havey, M.J. and W.T. Randle. 1996. Combining abilities for yield and bulb quality among long- and intermediate-day open-pollinated onion populations. J. Amer. Soc. Hort. Sci. 121:604-608.

Jones, H.A. and A. Clarke. 1943. Inheritance of male sterility in the onion and the production of hybrid seed. Proc. Amer. Soc. Hort. Sci. 43:189194.

Jones, H.A. and G. Davis. 1944. Inbreeding and heterosis and their relation to the development of new varieties of onions. USDA Tech. Bul. 874 .

King, J.J., J.M. Bradeen, O. Bark, J.A. McCallum, and M.J. Havey. 1998. A low-density genetic map of onion reveals the role of duplication in the evolution of an extremely large diploid genome. Theor. Appl. Genet. 96:52-62.

Mansur, L., K. Hadder, and J. Suarez. 1990. A computer program for calculating the population size necessary to recover any number of individuals exhibiting a trait. J. Hered. 81:407-408.

Pike, L.M. 1986. Onion breeding, p. 357-394. In: M.J. Bassett (ed.). Breeding vegetable crops. AVI Publ., Westport, Conn.

Wier, B. 1990. Genetic data analysis. Sinauer, Sunderland, Mass. 